\title{
Triterpene Glycosides from the Aerial Parts and Seeds of Bupleurum Falcatum
}

\author{
Venkata Sai Prakash Chaturvedula ${ }^{1}$, Indra Prakash ${ }^{2}$ \\ The Coca-Cola Company, Organic Chemistry Department, Global Research and Development, One Coca-Cola \\ Plaza, Atlanta, GA 30313, USA
}

\begin{abstract}
Phytochemical studies of the aqueous alcoholic extract of the aerial parts and seeds of Bupleurum falcatum furnished two known oleanane triterpene glycosides namely saikosaponin $A$, and saikosaponin D. The structures of the two isolated compounds 1-2 were characterized and their complete ${ }^{1} H$ and ${ }^{13} C$ NMR spectral assignments were made based on COSY, HMQC, and HMBC spectroscopic data as well as chemical studies.
\end{abstract}

Keywords: Bupleurum falcatum, Apiaceae, Triterpene glycosides, NMR, MS, Chemical studies, Structural characterization

\section{INTRODUCTION}

The genus Bupleurum is a well-known and very important crude drug in traditional oriental medicine, especially in Chinese and Japanese traditional medicine. Preparations containing the roots of Bupleurum species have been prescribed for more than 2000 years in Chinese traditional medicine [1-2] and have been used in the treatment of tumors and cancers. Bupleurum falcatum $L$. also known as Chinese thorough wax is a species of flowering plant belongs to the family of Apiaceae and is one of the most widely used components in traditional oriental medicines for the treatment of chronic hepatitis and auto-immune disease. Earlier phytochemical research has shown that the genus Bupleurum mainly accumulates saikosaponins [1-2]. As a part of our research to discover natural sweeteners, we have recently reported several diterpene glycosides from Stevia rebaudiana and Rubus suavissimus; triterpene glycosides from Siraitia grosvenorii; phenolic glycosides and sterols from $R$. suavissimus [3-12].

In this paper we are describing the isolation, purification and structural characterization of two known oleanane triterpene glycosides namely saikosaponin A (1), and saikosaponin D (2) that were assigned on the basis of $1 \mathrm{D}\left({ }^{1} \mathrm{H}\right.$ and $\left.{ }^{13} \mathrm{C}\right)$ and $2 \mathrm{D}$ (COSY, HSQC, and HMBC) NMR spectral data as well as chemical studies (Figure 1).
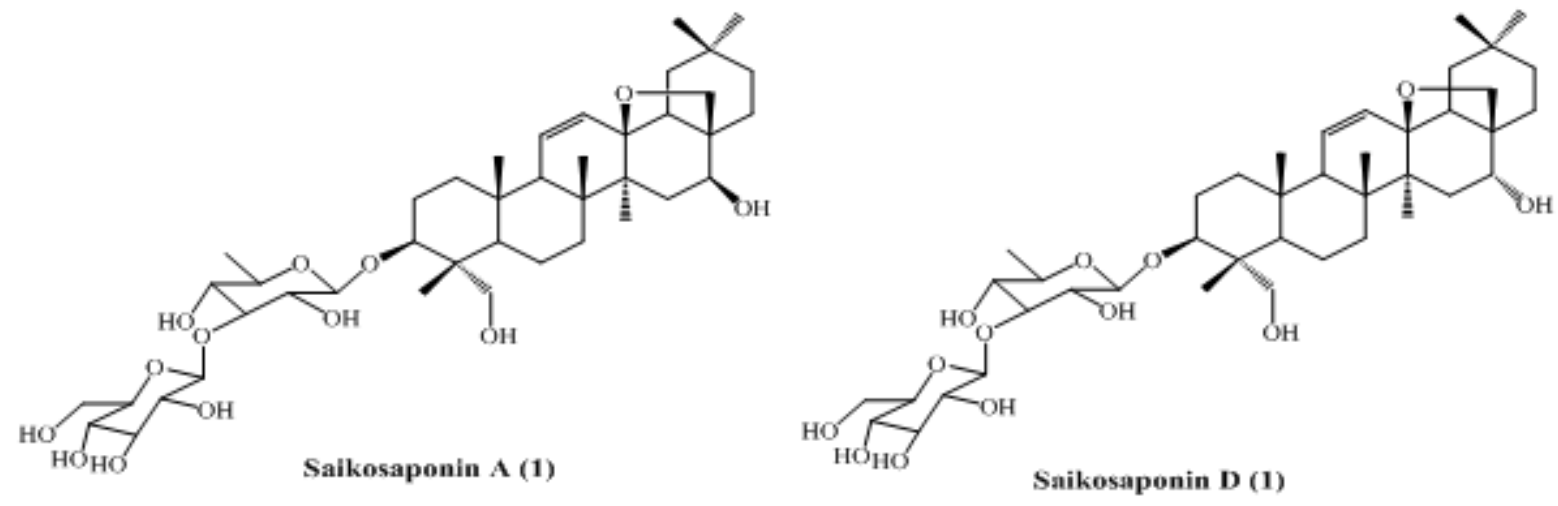

Figure 1: Structures of \$aikosaponin A (1) and \$aikosaponin D (2) 


\section{General Methods}

\section{MATERIALS AND METHODS}

NMR spectra were acquired on a Varian Unity Plus $600 \mathrm{MHz}$ instrument using standard pulse sequences at ambient temperature. Chemical shifts are given in $\delta(\mathrm{ppm})$, and coupling constants are reported in Hz. MS and MS/MS data were generated with a Waters Premier Quadrupole Time-of-Flight (Q-Tof) mass spectrometer equipped with an electrospray ionization source operated in the positive-ion mode and Thermo Fisher Discovery OrbiTrap in the Positive Mode Electrospray. Samples were diluted with water: acetonitrile (1:1) containing $0.1 \%$ formic acid and introduced via infusion using the onboard syringe pump at $\sim 10 \mathrm{ul} / \mathrm{min}$. Low pressure chromatography was performed on a Biotage Flash system using a C-18 cartridge (40+ M, 35-70 $\mu \mathrm{m})$. TLC was performed on Baker $\mathrm{Si}-\mathrm{C}_{18} \mathrm{~F}$ plates with mobile phase $\mathrm{H}_{2} \mathrm{O}-\mathrm{MeOH}(35: 65)$. Identification of the spots on the TLC plate was carried out by spraying $10 \% \mathrm{H}_{2} \mathrm{SO}_{4}$ in $\mathrm{EtOH}$ and heating the plate at about $80^{\circ} \mathrm{C}$. Analytical HPLC for sugar analysis was carried out with a Waters 600E multi-solvent delivery system using a Phenomenex Luna $\mathrm{C}_{18}$ non-chiral $(150 \times 4.6 \mathrm{~mm}, 5 \mu \mathrm{m})$ column.

\section{Materials}

A voucher specimen of the commercial extract is deposited at The Coca Cola Company, No. VSPC-3166-172.

\section{Isolation and Purification}

The aqueous alcoholic extract of the aerial parts and seeds of Bupleurum falcatum ( $25 \mathrm{~g})$ was purified on a C-18 column using a Biotage Flash chromatography system (Solvent system: gradient from 20-80\% $\mathrm{MeOH}$-water, $60 \mathrm{~mL} / \mathrm{min}$. Detection at UV $(210 \mathrm{~nm})$ by collecting 80 fractions. Fractions $58-68(0.85 \mathrm{~g})$ were combined and subjected to repeated Flash chromatography purification with gradient from $70-30 \% \mathrm{MeOH}-$ water, $25 \mathrm{~mL} / \mathrm{min}$ afforded saikosaponin $\mathrm{A}(\mathbf{1}, 58 \mathrm{mg})$ and saikosaponin $\mathrm{D}(\mathbf{2}, 64 \mathrm{mg})$.

\section{Identification of Saikosaponin A (1), and Saikosaponin D (2)}

Saikosaponin A (1): White amorphous powder; ESI-MS m/z $803[\mathrm{M}+\mathrm{Na}]^{+} ; \quad{ }^{1} \mathrm{H}$ NMR $\left(600 \mathrm{MHz}, \mathrm{C}_{5} \mathrm{D}_{5} \mathrm{~N}\right.$, ppm): $\delta 6.08(1 \mathrm{H}, \mathrm{d}, J=10.6 \mathrm{~Hz}, \mathrm{H}-12), 5.72(1 \mathrm{H}, \mathrm{dd}, J=2.6,10.4 \mathrm{~Hz}, \mathrm{H}-11), 5.38\left(1 \mathrm{H}, \mathrm{d}, J=8.1 \mathrm{~Hz}, \mathrm{Glc}-1^{\prime \prime}-\right.$ H), $4.98(1 \mathrm{H}, \mathrm{d}, J=7.4 \mathrm{~Hz}$, Fruc-1'-H), 4.42 (1H, m, H-16), 4.06 (1H, m, H-23), 3.92 (1H, m, H-23), $1.48(3 \mathrm{H}$, d, $J=6.8 \mathrm{~Hz}, \mathrm{H}-6$ '), 1.45 (3H, s, H-26), 1.15 (3H, s, H-27), 1.12 (3H, s, H-25), 0.98 (3H, s, H-29), 0.96 (3H, s, H-24), 0.93 (3H, s, H-30); ${ }^{13} \mathrm{C}$ NMR (150 MHz, $\left.\mathrm{C}_{5} \mathrm{D}_{5} \mathrm{~N}, \mathrm{ppm}\right): \delta 13.8(\mathrm{C}-24), 17.8(\mathrm{C}-6$ '), $18.2(\mathrm{C}-6), 19.4(\mathrm{C}-$ 25), 20.8 (C-26), 21.6 (C-27), 24.5 (C-30), 26.6 (C-22), 27.1 (C-2), 32.4 (C-20), 32.8 (C-7), 34.6 (C-29), 35.2 (C-21), 36.8 (C-15), 37.1 (C-10), 38.4 (C-19), 39.6 (C-1), 43.1 (C-8), 44.5 (C-4), 46.5 (C-14), 47.8 (C-17), 48.2 (C-5), 52.8 (C-18), 53.8 (C-9), 63.4 (C-6'), 64.8 (C-16), 64.6 (C-23), 71.8 (C-5'), 72.6 (C-2' ), 72.8 (C-4'), 73.2 (C-4"), 73.8 (C-28), 76.5 (C-2"), 79.1 (C-5"), 79.4 (C-3"), 82.3 (C-3), 84.6 (C-13), 86.1 (C-3'), 107.1 (C-1'), $107.6(\mathrm{C}-1 "), 132.1(\mathrm{C}-11), 133.0(\mathrm{C}-12)$.

Saikosaponin D (2): White amorphous powder; ESI-MS m/z $803[\mathrm{M}+\mathrm{Na}]^{+} ;{ }^{1} \mathrm{H}$ NMR $\left(600 \mathrm{MHz}, \mathrm{C}_{5} \mathrm{D}_{5} \mathrm{~N}, \mathrm{ppm}\right)$ : $\delta 6.12(1 \mathrm{H}, \mathrm{d}, J=10.8 \mathrm{~Hz}, \mathrm{H}-12), 5.67(1 \mathrm{H}, \mathrm{dd}, J=3.3,9.8 \mathrm{~Hz}, \mathrm{H}-11), 5.36\left(1 \mathrm{H}, \mathrm{d}, J=8.1 \mathrm{~Hz}, \mathrm{Glc}-1^{\prime \prime}-\mathrm{H}\right), 4.94$ $(1 \mathrm{H}, \mathrm{d}, J=7.4 \mathrm{~Hz}$, Fruc-1'-H), 4.26 (1H, m, H-16), 4.04 (1H, m, H-23), 3.90 (1H, m, H-23), $1.71(3 \mathrm{H}, \mathrm{s}, \mathrm{H}-25)$, $1.51(3 \mathrm{H}, \mathrm{d}, J=6.8 \mathrm{~Hz}, \mathrm{H}-6), 1.42$ (3H, s, H-27), 1.08 (3H, s, H-26), 1.10 (3H, s, H-29), 1.04 (3H, s, H-30), $0.98(3 \mathrm{H}, \mathrm{s}, \mathrm{H}-24) ;{ }^{13} \mathrm{C}$ NMR $\left(150 \mathrm{MHz}, \mathrm{C}_{5} \mathrm{D}_{5} \mathrm{~N}, \mathrm{ppm}\right): \delta 13.7(\mathrm{C}-24), 18.0(\mathrm{C}-6 \mathrm{\prime}), 18.3(\mathrm{C}-6), 18.8(\mathrm{C}-25), 19.7$ (C-26), 20.4 (C-27), 25.2 (C-30), 26.8 (C-2), 32.1 (C-22), 32.3 (C-20), 32.6 (C-7), 34.5 (C-29), 36.2 (C-21), 37.1 (C-15), 37.6 (C-10), 39.1 (C-19), 39.4 (C-1), 42.6 (C-8), 44.4 (C-4), 44.6 (C-14), 46.2 (C-17), 48.2 (C-5), 52.1 (C-18), 53.8 (C-9), 63.6 (C-6"), 64.8 (C-23), 71.8 (C-5'), 72.5 (C-2'), 72.6 (C-4'), 73.1 (C-4"), 76.6 (C-2"), 78.1 (C-16), 78.6 (C-28), 79.4 (C-5"), 79.6 (C-3"), 82.6 (C-3), 85.6 (C-13), 86.2 (C-3'), 107.1 (C-1'), 107.6 (C$1 "), 132.2$ (C-11), 133.1 (C-12).

Acid Hydrolysis of 1 and 2. To a solution of each compound 1 and 2 (1 mg) in $\mathrm{MeOH}(5 \mathrm{ml})$ was added $10 \mathrm{ml}$ of $5 \% \mathrm{H}_{2} \mathrm{SO}_{4}$ and the mixture was refluxed for 8 hours. The reaction mixture was then neutralized with saturated sodium carbonate and extracted with ethyl acetate (EtOAc) $(2 \times 5 \mathrm{ml})$ to give an aqueous fraction containing sugars and an EtOAc fraction containing the aglycone part. The aqueous phase was concentrated and compared with standard sugars using the TLC systems EtOAc/n-butanol/water (2:7:1) and $\mathrm{CH}_{2} \mathrm{Cl}_{2} / \mathrm{MeOH} /$ water (10:6:1); the two sugars were identified as D-fructose and D-glucose in the hydrolysis studies of $\mathbf{1}$ and 2 [13$14]$. 


\section{RESULTS AND DISCUSSION}

Compound $\mathbf{1}$ was isolated as a white powder. The mass spectral data of compound $\mathbf{1}$ gave a molecular ion peak at m/z 803 corresponding to its $(\mathrm{M}+\mathrm{Na})^{+}$ion suggesting the molecular formula as $\mathrm{C}_{42} \mathrm{H}_{68} \mathrm{O}_{13}$, which was supported by the ${ }^{13} \mathrm{C}$ NMR spectral data. Liebermann-Burchard reaction indicated compound $\mathbf{1}$ is having a terpenoid skeleton [15]. The ${ }^{1} \mathrm{H}$ NMR spectra of compound $\mathbf{1}$ showed the presence of six methyl signals at $\delta$ $0.93,0.96,0.981 .12,1.15$, and 1.45 ; one oxymethine proton as a multiplet at $\delta 4.42$; two oxymethylene protons as multiplets at $\delta 3.92$ and 4.06; and two protons of a disubstituted olefinic double bond at $\delta 5.72$ and 6.08 . The ${ }^{1} \mathrm{H}$ NMR spectra of compound $\mathbf{1}$ also showed the presence of a methyl doublet at $\delta 1.48$, and two anomeric protons at $\delta 4.38$ and 5.38, indicating the presence of two sugar units in its structure. Acid hydrolysis of $\mathbf{1}$ afforded D-fucose and D-glucose, which were identified by comparison with the authentic sugars by using by comparative TLC detection [13-14]. Additionally, the coupling constants for the anomeric proton of sugars in $\mathbf{1}$ indicated that the anomeric configurations of D-fucose and D-glucose as $\beta$. The ${ }^{13} \mathrm{C}$ NMR and distortionless enhancement polarization transfer (DEPT) spectra displayed 42 carbons which consisted of two carbons of a disubstituted double bond, two anomeric carbons, seven methyl groups, eight methylenes, three methines, six quaternary carbons and fourteen oxygen-bearing carbons. The presence of six methyl singlets and a disubstituted double bond suggested that compound $\mathbf{1}$ belongs to an oleanane type triterpenoid having a secondary hydroxyl and a primary hydroxyl groups along with a disubstituted double bond between C-11/C-12. The ${ }^{13} \mathrm{C}$ NMR values for all the protons and carbons were assigned on the basis of HMQC and HMBC correlations and were given in materials and methods. In order to confirm the linkages of the fructose and glucose sugar parts and the structure of the aglycone, heteronuclear multi-bond correlation (HMBC) experiments were carried out, suggested the structure as shown in Figure 2. Thus the structure of $\mathbf{1}$ was assigned as saikosaponin A, supported by comparison with the reported literature data [1-2].

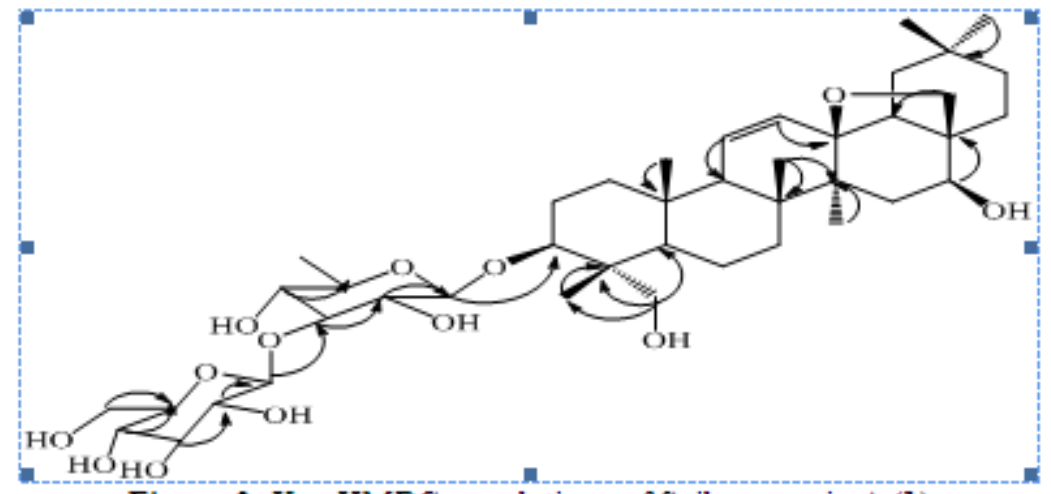

Figure 2: Key HMBC correlations of Saikosaponin A (1)

Compound $\mathbf{2}$ was also isolated as a white powder. The mass spectral data of compound $\mathbf{2}$ also gave a molecular ion peak at $\mathrm{m} / \mathrm{z} 803$ corresponding to its $(\mathrm{M}+\mathrm{Na})^{+}$ion similar to $\mathbf{1}$, suggesting the molecular formula as $\mathrm{C}_{42} \mathrm{H}_{68} \mathrm{O}_{13}$; supported by the ${ }^{13} \mathrm{C}$ NMR spectral data. Liebermann-Burchard reaction indicated compound $\mathbf{2}$ is having a terpenoid skeleton [15] as in $\mathbf{1}$. The ${ }^{1} \mathrm{H}$ NMR spectra of compound $\mathbf{2}$ showed the presence of six methyl signals as singlets, one oxymethine proton as a multiplet, two oxymethylene protons as multiplets, and two protons of a disubstituted olefinic double bond, same as $\mathbf{1}$. The ${ }^{1} \mathrm{H}$ NMR spectra of compound $\mathbf{2}$ also showed the presence of a methyl doublet, and two anomeric protons, indicating the presence of two sugar units in its structure. Acid hydrolysis of $\mathbf{2}$ afforded D-fucose and D-glucose, which was identified by comparison with the authentic sugars by using by comparative TLC detection [13-14], and the coupling constants for the anomeric proton of sugars indicated that the configurations of D-fucose and D-glucose as $\beta$; suggesting the presence of identical sugars in the compounds $\mathbf{1}$ and 2. The ${ }^{13} \mathrm{C}$ NMR and DEPT spectra displayed 42 carbons which consisted of two carbons of a disubstituted double bond, two anomeric carbons, seven methyl groups, eight methylenes, three methines, six quaternary carbons and fourteen oxygen-bearing carbons as in $\mathbf{1}$. The ${ }^{13} \mathrm{C}$ NMR values for all the protons and carbons were assigned on the basis of HMQC and HMBC correlations and were given in materials and methods. A close comparison of the ${ }^{1} \mathrm{H}$ and ${ }^{13} \mathrm{C}$ NMR data of compounds $\mathbf{1}$ and 2 suggested their identical nature of structures, except for the configuration of the hydroxyl group at C-16 position. Thus the structure of $\mathbf{2}$ was assigned as saikosaponin D, supported by comparison with the reported literature data ${ }^{1-2}$ and key HMBC correlations as shown in Figure 3 [1-2]. 


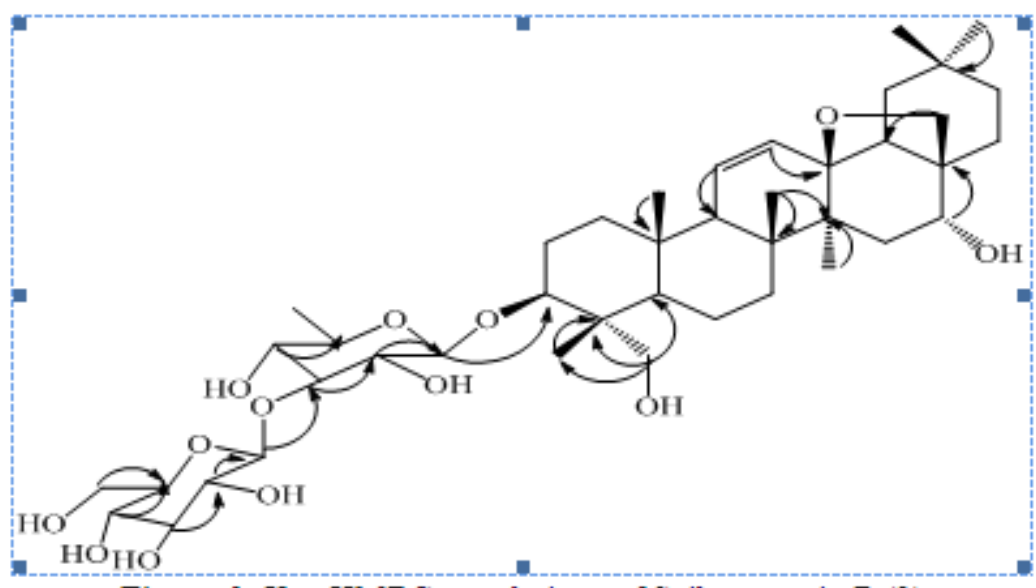

Figure 3: Key HMBC correlations of Saikosaponin D (2)

\section{CONCLUSIONS}

Two known oleanane triterpene glycosides namely saikosaponin A, and saikosaponin D were isolated from the aqueous alcoholic extract of the aerial parts and seeds of Bupleurum falcatum. The structures of the two isolated compounds 1-2 were characterized and their complete ${ }^{1} \mathrm{H}$ and ${ }^{13} \mathrm{C}$ NMR spectral assignments were made based on COSY, HMQC, and HMBC spectroscopic data as well as chemical studies.

\section{REFERENCES}

[1.] Nakahara, Y.; Okawa, M.; Kinjo, J.; Nohara, T. Oleanene glycosides of the aerial parts and seeds of Bupleurum falcatum and the aerial parts of Bupleurum rotundifolium, and their evaluation as anti-hepatitis agents. Chem. Pharm. Bull. 2011, 59, 1329-1339.

[2.] Yang, L.Z.; Li, C.; Min, L.X.; Qi, C.; Le, P.R. Cytotoxic saikosaponins from Bupleurum yinchowense. J. Med. Plants Res. 2012, 6, 4409-4415.

[3.] Chaturvedula, V.S.P.; Rhea, J.; Milanowski, D.; Mocek, U., Prakash, I. Two minor diterpene glycosides from the leaves of Stevia rebaudiana. Nat. Prod. Commun. 2011, 6, 175-178.

[4.] Chaturvedula, V. S. P.; Mani, U.; Prakash, I. Diterpene glycosides from Stevia rebaudiana. Molecules. 2011, 16, 3552-3562.

[5.] Chaturvedula, V. S. P.; Prakash, I. A new diterpenoid glycoside from Stevia rebaudiana. Molecules. 2011, 16, 2937-2943.

[6.] Chaturvedula, V. S. P.; Prakash, I. Structures of the novel diterpene glycosides from Stevia rebaudiana. Carbohydr. Res. 2011, 346, 1057-1060.

[7.] Chaturvedula, V. S. P.; Rhea, J.; Milanowski, D.; Mocek, U.; Prakash, I. Two minor diterpene glycosides from the leaves of Stevia rebaudiana. Nat. Prod. Commun. 2011, 6, 175-178.

[8.] Chaturvedula, V. S. P.; Prakash, I. Additional minor diterpene glycosides from Stevia rebaudiana. Nat. Prod. Commun. 2011, 6, 1059-1062.

[9.] Chaturvedula, V.S.P.; Clos, J.F.; Rhea, J.; Milanowski, D.; Mocek, U., DuBois, G.E.; Prakash, I. Phytochemistry Lett. 2011, 4, 209-212.

[10.] Chaturvedula, V. S. P.; Mani, U.; Prakash, I. Structures of the novel $\alpha$-glucosyl linked diterpene glycosides from Stevia rebaudiana. Carbohydr. Res. 2011, 346, 2034-2038.

[11.] Chaturvedula, V.S.P.; Prakash, I. Curcubitane Glycosides from Siraitia grosvenorii, J. Carbhydr. Chem, 2011, 30, 16-26.

[12.] Chaturvedula, V.S.P.; Prakash, I. Kaempferol glycosides from Siraitia grosvenorii, J. Chem. Pharm. Res., 2011, 3, 799-804.

[13.] Bedir, E.; Toyang, N.J.; Khan, I.A.; Walker, L.A.; Clark, A.M. A new dammarane type triterpene glycoside from Polyscias fulva. J. Nat. Prod, 2001, 64, 95-97.

[14.] Huan, V.D.; Yamamura, S.; Ohtani, K.; Kasai, R.; Yamasaki, K.; Nham, N.T. Oleanane saponins from Polyscias fructicosa. Phytochemistry, 1998, 47, 451-457.

[15.] An, R.B.; Kim, H.C.; Jeong, G.S.; Oh, SH, O.h H.; Kim, Y.-C. Constituents of the aerial parts of Agrimonia pilosa. Nat. Prod. Sci. 2005, 11, 196-198. 